\title{
Acquired aortic nipple: a potential sign of deep venous obstruction
}

\author{
Douglas W. Byerly • Alan E. Schlesinger
}

Received: 9 May 2010 / Accepted: 2 June 2010 / Published online: 8 July 2010

(C) Springer-Verlag 2010

A 17-year-old boy presented with gynecomastia and multiple firm testicular nodules. The boy underwent a right radical orchiectomy and chemotherapy for mixed germ cell testicular neoplasm. After treatment, follow-up chest radiographs and the scout image from a surveillance $\mathrm{CT}$ demonstrated a new finding of an aortic nipple (Fig. 1, arrow) that was not present on previous chest radiographs or CT scans. The $\mathrm{CT}$ revealed new thrombus within the left innominate vein with collateral

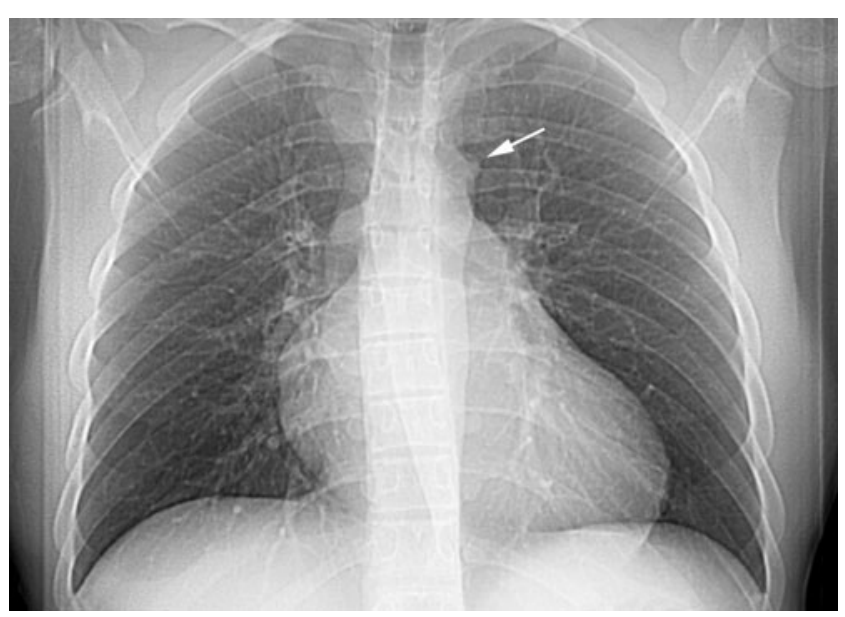

Fig. 1 Scout image from a chest CT

D. W. Byerly

Department of Radiology, San Antonio Uniformed Health Education Consortium,

Wilford Hall Medical Center, 2200 Bergquist Dr., Suite 1, Lackland Air Force Base,

San Antonio, TX 78236, USA

\section{A. E. Schlesinger $(\bowtie)$}

Department of Radiology, Baylor College of Medicine,

Texas Children's Hospital,

6621 Fannin St., MC-CC470.01,

Houston, TX 77030, USA

e-mail: alanschlesinger@mac.com

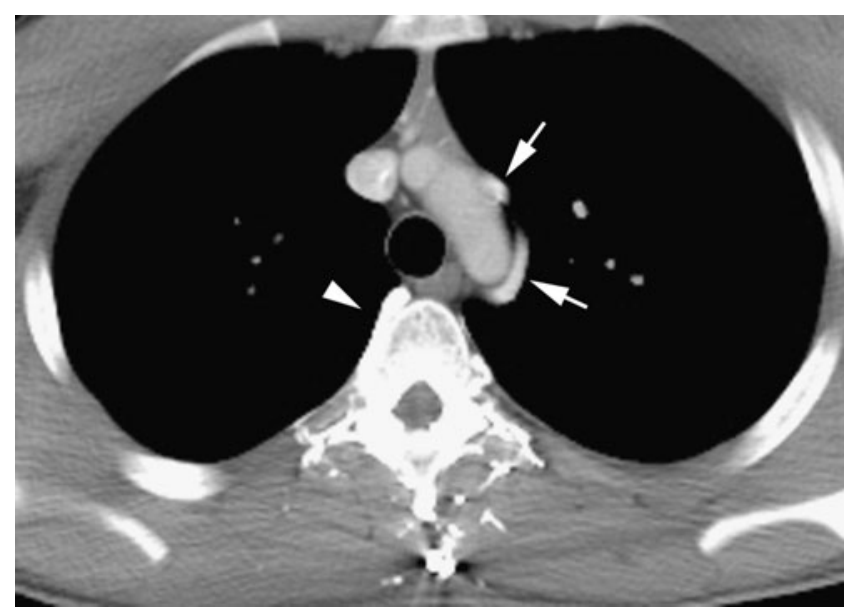

Fig. 2 Axial CT image

flow through the left superior intercostal vein (arrows) and paravertebral veins, which drained into the azygos vein (arrowhead) (Fig. 2). More cranial images (not shown) revealed a new left innominate vein thrombus.

The aortic nipple is a normal variant seen on chest radiographs in $1-9 \%$ of the population and is caused by a prominent left superior intercostal vein adjacent to the aortic arch [1]. However, it has also been reported in patients with congenital vascular abnormalities or obstruction of the superior vena cava (SVC), inferior vena cava (IVC) or innominate veins. Therefore, the development of a new aortic nipple on a chest radiograph should raise concern for innominate vein, SVC or IVC thrombosis $[1,2]$.

\section{References}

1. Friedman AC, Chambers E, Sprayregen S (1978) The normal and abnormal left superior intercostal vein. Am J Roentgenol 131:599-602

2. Parker MS, Rosado de Christenson ML, Abbott GF (2005) Teaching atlas of chest imaging. Thieme, New York 